\title{
Fish swimming in schools save energy regardless of their spatial position
}

\author{
Stefano Marras • Shaun S. Killen • Jan Lindström • \\ David J. McKenzie • John F. Steffensen • Paolo Domenici
}

Received: 23 May 2014 / Revised: 14 October 2014 / Accepted: 14 October 2014 / Published online: 30 October 2014

(C) Springer-Verlag Berlin Heidelberg 2014

\begin{abstract}
For animals, being a member of a group provides various advantages, such as reduced vulnerability to predators, increased foraging opportunities and reduced energetic costs of locomotion. In moving groups such as fish schools, there are benefits of group membership for trailing individuals, who can reduce the cost of movement by exploiting the flow patterns generated by the individuals swimming ahead of them. However, whether positions relative to the closest neighbours (e.g. ahead, sided by side or behind) modulate the individual energetic cost of swimming is still unknown. Here, we addressed these questions in grey mullet Liza aurata by measuring tail-beat frequency and amplitude of 15 focal fish, swimming in separate schools, while swimming in isolation and in various positions relative to their closest neighbours, at three speeds. Our results demonstrate that, in a fish school, individuals in any position have
\end{abstract}

Communicated by D. P. Croft

Stefano Marras and Shaun S. Killen contributed equally to the manuscript.

S. Marras $(\bowtie) \cdot$ P. Domenici

IAMC-CNR, Institute for the Coastal Marine Environment, National

Research Council, Localita' Sa Mardini, 09170 Torregrande,

Oristano, Italy

e-mail: stefano.marras@cnr.it

S. S. Killen $\cdot$ J. Lindström

Institute of Biodiversity, Animal Health and Comparative Medicine,

College of Medical, Veterinary and Life Sciences, Graham Kerr

Building, University of Glasgow, Glasgow G12 8QQ, Scotland, UK

\section{J. McKenzie}

Ecologie des Systèmes Marins Côtiers, UMR5119, Université Montpellier 2, Place Eugène Bataillon, 34095 Montpellier cedex 5, France

\section{J. F. Steffensen}

Marine Biological Laboratory, University of Copenhagen,

Strandpromenaden 5, 3000 Helsingør, Denmark reduced costs of swimming, compared to when they swim at the same speed but alone. Although fish swimming behind their neighbours save the most energy, even fish swimming ahead of their nearest neighbour were able to gain a net energetic benefit over swimming in isolation, including those swimming at the front of a school. Interestingly, this energetic saving was greatest at the lowest swimming speed measured in our study. Because any member of a school gains an energetic benefit compared to swimming alone, we suggest that the benefits of membership in moving groups may be more strongly linked to reducing the costs of locomotion than previously appreciated.

Keywords Collective behaviour · Hydrodynamics . Energetics $\cdot$ Ecophysiology

\section{Introduction}

Living in groups can provide a number of costs and benefits to animals (Krause and Ruxton 2002). The costs of group membership include an increased risk of predation in some contexts (Krause and Godin 1995), aggression among group members (Krause and Ruxton 2002) and parasitism (Poulin 1999). As a consequence, animals presumably only aggregate when such disadvantages are outweighed by benefits in various behaviours such as those related to individual predator avoidance (Godin 1997), foraging success (Pitcher and Parrish 1993) and locomotor activity (Herskin and Steffensen 1998; Fish 1999; Johansen et al. 2010; Killen et al. 2012). Assessing a particular cost/benefit ratio for any given individual is not, however, simple because it can depend upon its spatial position and hierarchical role in the group and on its physiological condition (Krause et al. 1992; Bumann et al. 1997; Svendsen et al. 2003; Killen et al. 2012; Marras 
et al. 2012; Marras and Domenici 2013). For example, animals in the front of the moving groups can have higher feeding success (Krause and Ruxton 2002) but also increased risks of predation (Bumann et al. 1997).

A widely appreciated benefit of group membership is the reduction in cost of locomotion for individuals that trail behind others, taking advantage of the vortices (e.g. birds flying in a V formation or fish schooling (Weihs 1973; Cutts and Speakman 1994; Weimerskirch et al. 2001; Portugal et al. 2014)) or zones of low pressure (e.g. bicyclists drafting in a peloton or vehicles on a motorway) created by their leading group mates (McCole et al. 1990; Dominy 1992; Fish 1999). Despite few rare documented cases of an increased energetic expenditure provided by moving in groups [e.g. flocking pigeons (Usherwood et al. 2011)], such energetic savings can be significant enough to be considered one of the main benefits of group membership for schooling fish, flocking birds and cycling humans (Fish 1999; Krause and Ruxton 2002; Liao et al. 2003a).

Fish schools exhibit fascinatingly polarised movements, and hydrodynamic efficiency is therefore considered an important benefit of group membership (Belyayev and Zuyev 1969; Weihs 1973). Within a school, trailing individuals can exploit the reverse von Karman street vortices produced by fish further ahead within the group to reduce their own costs of forward movement (Fish et al. 1991; Liao et al. 2003a; Svendsen et al. 2003; Killen et al. 2012; Marras and Porfiri 2012). Fish at the front of a school incur higher costs of swimming than those trailing, and at higher speeds, individuals with lower aerobic scope may shuffle toward the rear to take advantage of the energetic savings (Killen et al. 2012). Recent theoretical studies have, however, suggested that the flow dynamics around fish swimming in schools could also provide energetic benefits compared to swimming in isolation (Hemelrijk et al. 2014), even for fish swimming beside their nearest neighbour. While previous empirical studies have compared the energetic cost of swimming in anteriorly and posteriorly positioned fish, the assessment of the advantages of group living must, by definition, be based on the comparison against a state of being alone. In this study, we determined how an individual's position relative to its nearest neighbour affects individual energy expenditure when swimming in a school, to investigate the possibility that even individuals swimming in the front of their closest neighbour can save energy compared to when they swim in isolation. We measured tail-beat frequency of individually marked fish (focal fish) at a variety of speeds when swimming alone and compared this to their tail-beat frequency when swimming in various positions relative to their closest neighbours. We then used measured relationships between tail-beat frequency and activity metabolism to estimate the relative energetic costs of swimming at these different positions.

\section{Methods}

Animals

Juvenile golden grey mullet (Liza aurata), a gregarious species, were collected by seine nets in summer on the coast of the Mediterranean Sea near Sète, France (43 24' 19" $\left.\mathrm{N} 3^{\circ} 41^{\prime} 51^{\prime \prime} \mathrm{E}\right)$. Once at the lab (Station Méditerranéenne de l'Environnement Littoral, Sète, France) they were held for at least 4 weeks in large tanks $(100 \mathrm{~cm} \mathrm{~L} \times 100 \mathrm{~cm} \mathrm{~W} \times 60 \mathrm{~cm} \mathrm{H})$ supplied with local sea water at a salinity of 35 , in a biofiltered recirculation system at $20^{\circ} \mathrm{C}$ under a natural photoperiod and fed four times a week with commercial pellets (Aphytec, Mèze, France). Feeding was halted at least $36 \mathrm{~h}$ before experiments.

\section{Swimming performance}

A 30-L Steffensen-type swimming tunnel (Loligo system, Tjele, Denmark, www.loligosystems.com) was used to test the fish. The tunnel was designed to swim the fish in a nonturbulent laminar flow at different water speeds. The working section, laterally covered with non-reflecting material to avoid mirror effects, was $55 \mathrm{~cm} \mathrm{~L} \times 14 \mathrm{~cm} \mathrm{~W} \times 14 \mathrm{~cm} \mathrm{H}$. The swimming tunnel was thermo-regulated at $20 \pm 0.5^{\circ} \mathrm{C}$. A total of 15 schools, with eight different fish in each (mean total length \pm S.E. $=12.02 \pm 0.11 \mathrm{~cm}$ ), were tested for their swimming performance. For each school, one of the eight members (focal fish) was then randomly chosen and tested while swimming alone (mean total length \pm S.E. $=12.03 \pm 0.24 \mathrm{~cm}$; mean width \pm S.E. $=1.66 \pm 0.1 \mathrm{~cm}$; mean height \pm S.E. $=1.4 \pm 0.1 \mathrm{~cm}$ ). Each fish was marked dorsally in front of the dorsal fin for individual discrimination during video analysis (Marras and Domenici 2013), with insoluble non-toxic white Titanium (IV) oxide powder (Sigma) mixed into cyanoacrylate glue (Marras and Domenici 2013). Different symbols of approximately $0.5 \times 0.5 \mathrm{~cm}$ were used for each fish, clearly visible with a video camera (Sony Mini DV recording at 25 frames per second) positioned above the swimming tunnel.

To evaluate swimming in schools, eight fish were acclimated to the tunnel at a current speed of $10 \mathrm{~cm} \mathrm{~s}^{-1}$ for $5 \mathrm{~h}$ and then their swimming was recorded for $20 \mathrm{~min}$. Current velocity was gradually increased to $20 \mathrm{~cm} \mathrm{~s}^{-1}$ over $5 \mathrm{~min}$ and the school was allowed $1 \mathrm{~h}$ to acclimate. After $20 \mathrm{~min}$ of recording, at the end of this hour, current velocity was increased to $30 \mathrm{~cm} \mathrm{~s}^{-1}$, and the mullet acclimated and filmed as for the $20 \mathrm{~cm} \mathrm{~s}^{-1}$. The choice of swimming the fish at $30 \mathrm{~cm} \mathrm{~s}^{-1}$ depends on the fact that such speed approach the maximum sustained speed (without engaging in burst-type swimming) of the mullet of that was used for the experiments. Current velocity was then reduced back to zero, fish removed from the tunnel, weighed and measured for length, width and height and placed in an individual tank with a flow of water identical to the initial acclimation tank. After 2 days of recovery from 
the schooling test, the focal fish was placed in the swim tunnel and exposed to the same swimming protocol in isolation.

Videos were analysed to estimate the tail-beat frequency (TBF) and tail-beat amplitude (TBA) of the focal fish swimming in isolation. TBF and TBA were also measured when the focal fish was swimming in school; however, position ranking and position relative to neighbour were also noted at the time of the measurement. Position ranking of the focal fish relative to the other individuals was based on to the position of the snout of the focal fish in relation to the front of the school. The focal fish was measured when swimming in seven different positions, along its longitudinal axis, relative to the closest neighbour at a lateral distance of between 0.4 and 0.5 of its body length (BL) (Fig. 1a). Specifically, the focal fish was considered in position 0 when the angle $(\alpha)$ between the segment joining the centre of mass and the tip of the head of the nearest neighbour and the segment between its centre of mass and that of its nearest neighbour was $90^{\circ}$ (i.e. the focal fish and neighbour were swimming side by side). The focal fish was considered in frontal position 0.25 , relative to its closest neighbour, when $\alpha$ was between 65 and $75^{\circ}$, meaning approximately $0.25 \mathrm{BL}$ anterior of the nearest neighbour. A relative frontal position of 0.75 was assigned when $\alpha$ was between 35 and $45^{\circ}$ and relative frontal 1.25 when $\alpha$ ranged from 20 to $25^{\circ}$. Posterior positions were also assigned by the same rules as for frontal positions. Specifically, the focal fish was swimming in a posterior position of -0.25 , relative to its closest neighbour, when $\alpha$ was between 105 and $115^{\circ},-0.75$ when $\alpha$ ranged from 135 to $145^{\circ}$ and -1.25 when $\alpha$ was measured between 155 and $165^{\circ}$ (see Fig. 1a for a detailed illustration of the different positions assigned to the focal fish). Note that no individual, other that the nearest neighbour, was swimming ahead of the focal fish at the time of the measurements. Note also that TBF of fish swimming in a swim tunnel can be affected by the closest distance from the walls of the tunnel (Webb 1993). To minimise any confounding effects of distance from the wall, the TBF of focal fish was never measured when they were swimming at a distance $<0.3 \mathrm{BL}$ from the swim tunnel walls.

\section{Estimation of energetic costs}

Energetic costs were estimated as rates of oxygen uptake $\left(\mathrm{MO}_{2}\right)$ in two steps: (i) the swimming speed $\left(U_{\mathrm{es}}\right)$ equivalent to a given tail-beat frequency (TBF) was estimated using the relationship between TBF and swimming speed (in $\mathrm{BL} \mathrm{s}^{-1}$ ) of the solitary fish [i.e. $U_{\mathrm{es}}=1.1214(\mathrm{TBF})-0.6905, R^{2}=0.33$ (linear regression, $p<0.001$ )] and (ii) the relationship between $U_{\text {es }}$ and $\mathrm{MO}_{2}$ was calculated from the line connecting metabolic rate at rest (standard metabolic rate, SMR) and at exhaustion (maximum metabolic rate, MMR) in a semi-Log plot with $\mathrm{SMR}=197.64 \mathrm{mg} \mathrm{O} \mathrm{h}^{-1} \mathrm{~kg}^{-1}$ and $\mathrm{MMR}=$ $672.65 \mathrm{mg} \mathrm{O}_{2} \mathrm{~h}^{-1} \mathrm{~kg}^{-1}$, based on data for the same individuals

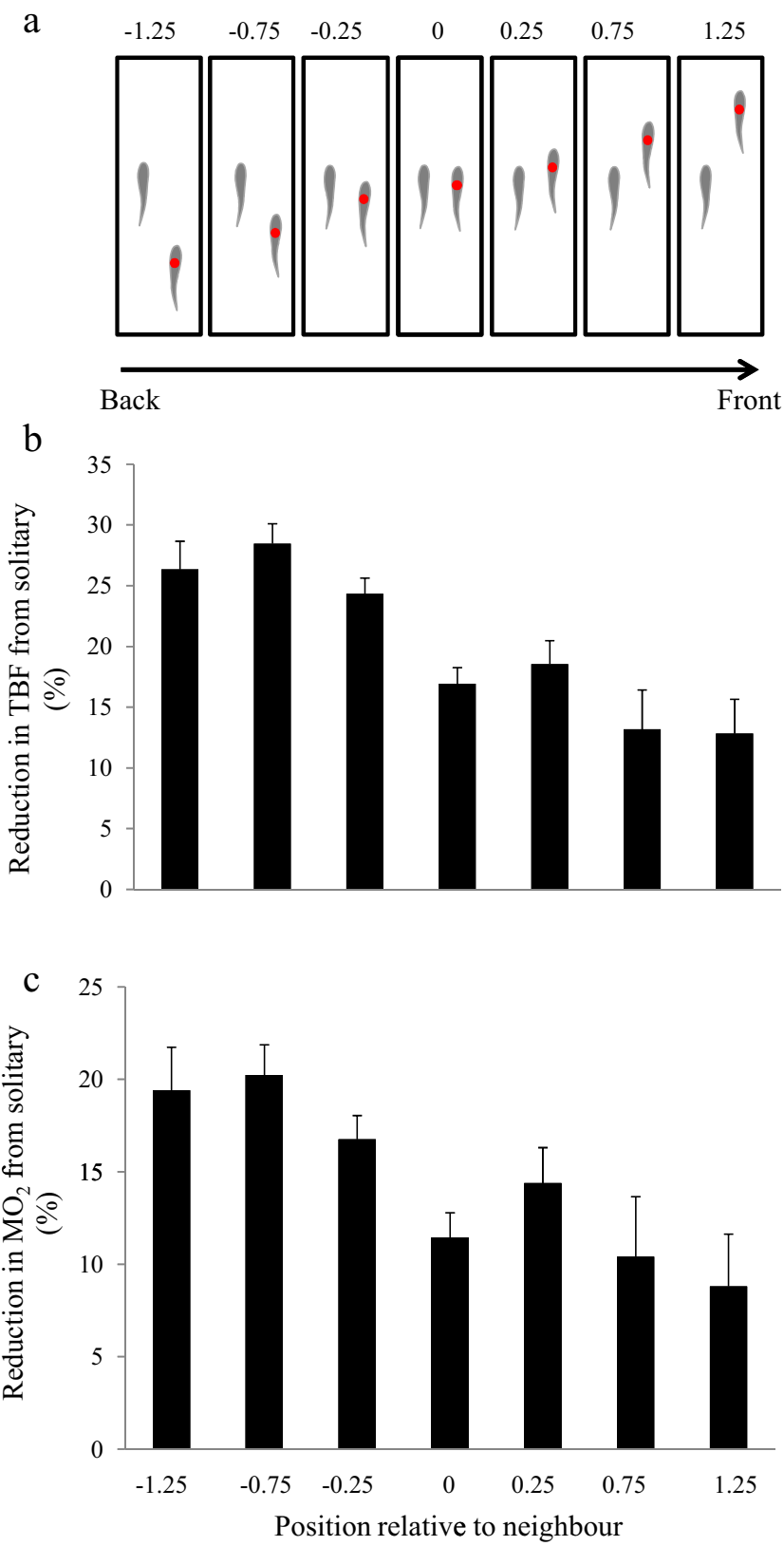

Fig. 1 a Positions of the focal fish (red dot) relative to its closest neighbour. At negative values, the focal fish was swimming behind its closest neighbour, 0 represents swimming side by side, and at positive values, the focal fish was ahead of its closest neighbour. Note that for clarity, the other six school members are not shown in the figure. $\mathbf{b}$ Reduction in TBF (\%) of focal fish when swimming in different positions in a school, compared to swimming alone. Bar values refer to the position represented above in panel a. Values are mean \pm S.E. c Reduction in the estimated metabolic rate $\left(\mathrm{MO}_{2}\right)$ compared to solitary swimming in juvenile golden grey mullet while swimming in various positions relative to a neighbour in a school. Values are mean \pm S.E.

measured in Killen et al. (2012). Speed at SMR was considered 0 , while speed at MMR was estimated based on the relationship between fish length and the maximum sustained swimming speed $\left(U_{\mathrm{ms}}\right)$ in teleosts (based on the equation $U_{\mathrm{ms}}=0.15+2.4 \mathrm{~L}_{\text {in m s}}^{-1}$, from Videler (Videler 1993)). 
Data and statistical analyses

Due to the repeated measurements on the same individuals in the data, we used a general mixed effects model for the analysis of tail-beat frequency (TBF). We analysed these data in two ways, by looking at the TBF as such and also by looking at the percentage change in TBF when a fish was alone in a swim tunnel and when they were in a group (i.e. the reduction in percentage of TBF of the focal fish swimming in group compared to when swimming in isolation). In both cases, we first constructed a full model where fish identity was included as a random factor, and swim speed (later, simply speed), rank and position were included as categorical fixed effects (with 3, 8 and 7 levels, respectively), standard length as a covariate and all two-way interactions. To find the most parsimonious models in each case, we followed a standard procedure in model selection (Zuur et al. 2009). The full model was first fitted by using restricted maximum likelihood estimation (REML) to compare the possible random structures by likelihood ratio testing. Initial data exploration showed that there is a lot of individual variation in how the fish react to speed and position, so to take this into account, we compared the random intercept model with fish identity fitted as a random factor with random slope models where the slope estimates were allowed to vary between individuals either for speed, position or both. We then proceeded with model selection by using maximum likelihood estimation, dropping variables one by one, starting with the ones with smallest $t$ values, and left them in the model if their removal resulted in a poorer model (significantly larger Akaike information criterion (AIC) value as indicated by likelihood ratio tests, LRT). We also visually inspected the residuals against fitted values to ensure that the assumption of models with Gaussian error structure having normally distributed and homogenous residuals was fulfilled.

After the model selection procedure, the final models' parameters were then estimated by fitting the most parsimonious models again using REML as suggested by Zuur et al. (2009). For the final models, we also calculated two different $R^{2}$ values to quantify their overall performance: marginal $R^{2}$ $\left(R_{\mathrm{m}}^{2}\right)$ and conditional $R^{2}\left(R_{\mathrm{c}}^{2}\right)$ which indicated the variance explained by fixed factors and by both fixed and random factors, respectively (Nakagawa and Schielzeth 2013).

These mixed effects models were fitted using $\mathrm{R}$ (version 2.15.3, R Development Core Team, the R Foundation for Statistical Computing, Vienna, Austria, http://www.r-project. org), using the function lmer in package lme4 (Bates et al. 2011) and MuMIn 1.9.13 (http://CRAN.R-project.org/ package $=$ MuMIn).

To specifically test whether all school members, including those swimming at the very front of the school (rank=1) gain an energetic advantage relative to swimming alone or at any other position within a school, we constructed a linear mixed effects model (LME) with tail-beat frequency as the response variable and swimming speed and context as explanatory variables. Fish ID was also included as a random effect on the slope and intercept of the model, to account for repeated measures on the same individuals across contexts and speeds. The term "context" consisted of three levels: 1) swimming in solitary, 2) swimming in position 1, and 3) swimming in positions $2-8$ within the school. Values for TBF were the mean values across all measurements taken within a given context. The original LME also included the interaction between swim speed and context. This interaction was non-significant and was therefore removed and the model rerun.

\section{Results}

Position relative to neighbour and swimming speed both had significant effects on the reduction in TBF compared to when the same fish was swimming in isolation (LRT position: $\chi^{2}=$ 110.7, $d f=6, p<0.0001$; LRT speed: $\chi^{2}=16.8, d f=2, p=$ 0.0002 ), but there was no interaction between these two factors. There was a greater reduction in TBF when focal fish were behind their nearest neighbour (i.e. average of the positions $<0$ ) than when they were ahead (i.e. average of the positions $>0$, Fig. 1b). Although there was a general reduction in TBF at all three swimming speeds, when compared to swimming in isolation, the fish in a school showed the greatest overall reduction in TBF at the lowest speed (Fig. 2a). Rank from the front of the school was not a significant explanatory variable (i.e. it had no main effect or interaction with position) and was dropped from the most parsimonious generalized linear mixed model (GLMM), which only included swimming speed and position. Tail-beat amplitude never varied in relation with TBF, speed or position (GLMM, $p>0.05$ for all terms). Linear and non-linear wall distances were not included in the model since including it as a factor is not justified in either the solitary or group context (LRT for including wall distance; solitary: significant reduction in model performance $p=0.0007$, group: no difference in model performance $p=0.68$ ).

The optimal random structure of the model included a random intercept estimation for fish as well as random slope estimation for speed, TBF and percentage change of TBF. TBF and percentage change in TBF were both best explained by models which included speed and position relative to the closest neighbour (Tables 1 and 2); TBF model, but not percentage change in TBF model, also included standard length. TBF increased with speed and decreased with position relative to neighbour (i.e. higher reduction in posterior position and lower reduction in anterior position) and standard length (Table 1). The results of the percentage change model (which refers to the percentage reduction in TBF of the focal 


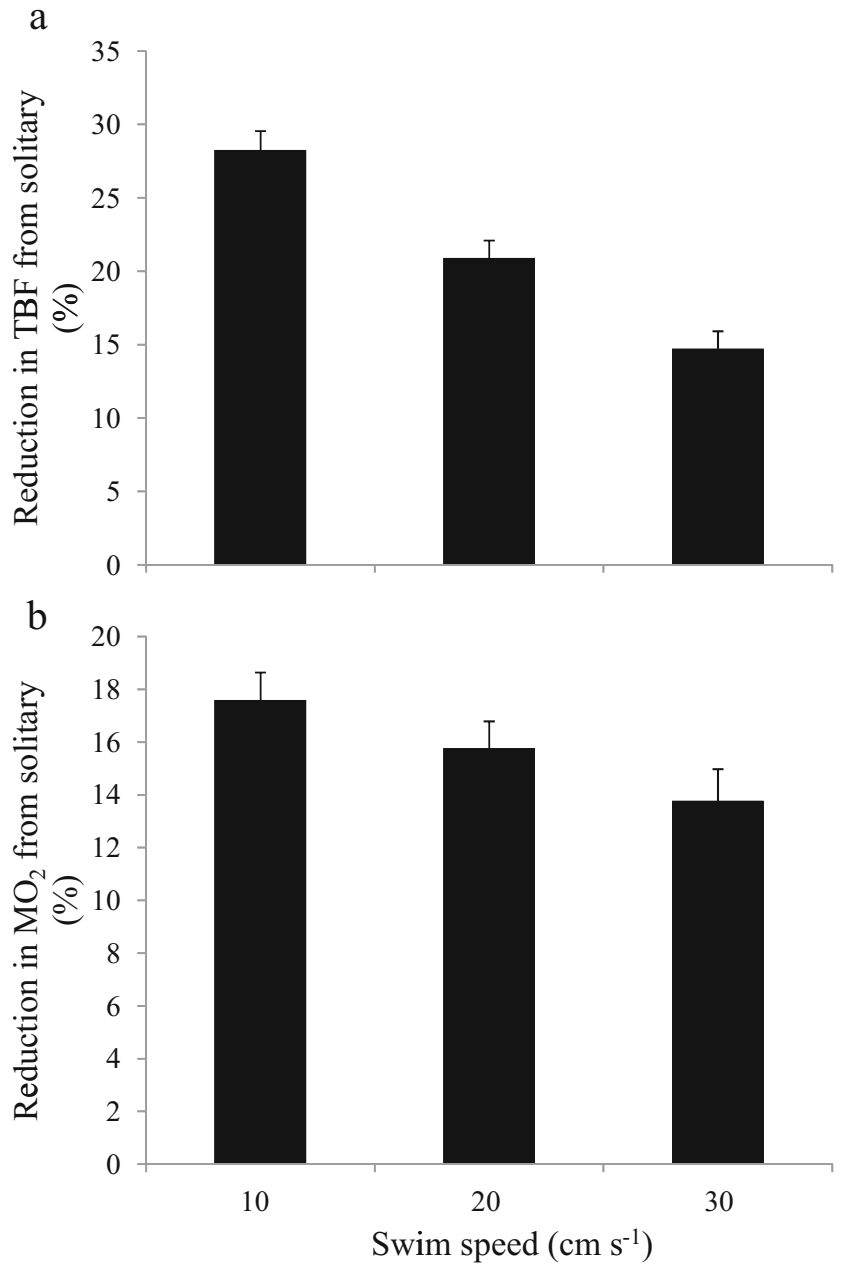

Fig. 2 a Reduction in TBF (\%) of focal fish when swimming at three different water speeds in a school relative to swimming alone. Values are mean \pm S.E. $\mathbf{b}$ Reduction in the estimated metabolic rate $\left(\mathrm{MO}_{2}\right)$ compared to solitary swimming in juvenile golden grey mullet while swimming at various speeds. Values are mean \pm S.E.

fish when swimming in school compared to when swimming in isolation) showed an increased degree of change with speed and position; in other words, the further back relative to its closest neighbour a fish is, the more energy it saves relative to being alone. In both cases, the final models performed well: their $R_{\mathrm{m}}^{2}$ and $R^{2}{ }_{\mathrm{c}}$ values were 0.76 and 0.90 , and 0.12 and 0.92 for TBF and relative TBF, respectively.

In terms of the estimated $\mathrm{MO}_{2}$, fish in the most posterior position relative to their neighbour (position -1.25) used about $10.6 \%$ less energy per unit time than those in the most anterior positions (1.25) (Fig. 1c). Relative to swimming in isolation, estimates of energy savings ranged from 8.8 to $19.4 \%$ depending on position, with individuals ahead of their neighbour saving less energy $(8.8 \%)$ than those behind their neighbour (19.4 \%) (Fig. 1c). When compared to swimming in isolation, fish in a school showed a greater overall reduction in the estimated $\mathrm{MO}_{2}$ at the lowest speed than at the highest speed (Fig. 2b).
Table 1 Summary of the most parsimonious mixed-effects models to explain tail beat frequency

\begin{tabular}{lccrr}
\hline Variable & $\begin{array}{c}\text { Parameter } \\
\text { estimate }\end{array}$ & Std. error & \multicolumn{1}{c}{$X^{2}$} & \multicolumn{1}{c}{$p$} \\
Intercept & 3.017 & 0.371 & & \\
Speed(20) & 0.335 & 0.022 & 47.82 & $<0.0001$ \\
Speed(30) & 0.698 & 0.039 & & \\
Standard length & -0.153 & 0.034 & 12.91 & 0.0003 \\
Pos(-0.75) & -0.00004 & 0.022 & 103.06 & $<0.0001$ \\
Pos(-0.25) & 0.089 & 0.024 & & \\
Pos(0) & 0.162 & 0.025 & & \\
Pos(0.25) & 0.224 & 0.026 & & \\
Pos(0.75) & 0.226 & 0.039 & & \\
Pos(1.25) & 0.248 & 0.067 & & \\
& & & & \\
Random effects & Variance & Std. & & \\
Fish (intercept) & 0.014 & 0.119 & & \\
Fish (intercept) & 0.011 & 0.104 & & \\
Speed(20) & 0.005 & 0.067 & & \\
Speed(30) & 0.020 & 0.141 & & \\
Residual & 0.015 & 0.121 & & \\
\hline
\end{tabular}

Fish swimming at the front of the school (i.e. rank \#1) spent less energy compared to when swimming in solitary (Fig. 3; Table 3; LME, effect of context, $F=29.66, p<0.001$; pairwise comparisons of marginal means, rank \#1 vs. solitary: $p<0.001)$. However, although TBF tended to be higher in fish in position rank \#1 compared to fish in positions rank \#2 to rank \#8, there was a large overlap between the $95 \%$ CIs on their parameter estimates, and the pairwise comparison showed no significant differences (LME, pairwise comparison

Table 2 Summary of the most parsimonious mixed-effects models to explain relative tail beat frequency

\begin{tabular}{lrrrr}
\hline Variable & $\begin{array}{c}\text { Parameter } \\
\text { estimate }\end{array}$ & Std. error & \multicolumn{1}{l}{$X^{2}$} & $p$ \\
Intercept & 32.479 & 4.144 & & \\
Speed(20) & -6.011 & 1.686 & 16.82 & 0.0002 \\
Speed(30) & -11.722 & 2.316 & & \\
Pos(-0.75) & 0.163 & 0.896 & 110.76 & $<0.0001$ \\
Pos(-0.25) & -3.699 & 0.958 & & \\
Pos(0) & -6.743 & 1.007 & & \\
Pos(0.25) & -9.437 & 1.071 & & \\
Pos(0.75) & -10.135 & 1.587 & & \\
Pos(1.25) & -10.568 & 2.696 & & \\
& & & & \\
Random effects & Variance & Std. & & \\
Fish (intercept) & 77.190 & 8.786 & & \\
Fish (intercept) & 169.91 & 13.035 & & \\
Speed(20) & 37.820 & 6.150 & & \\
Speed(30) & 75.660 & 8.698 & & \\
Residual & 23.490 & 4.846 & \\
\hline
\end{tabular}


- Solitary $\square$ Rank \#1 aRank\#2-8 (pooled)

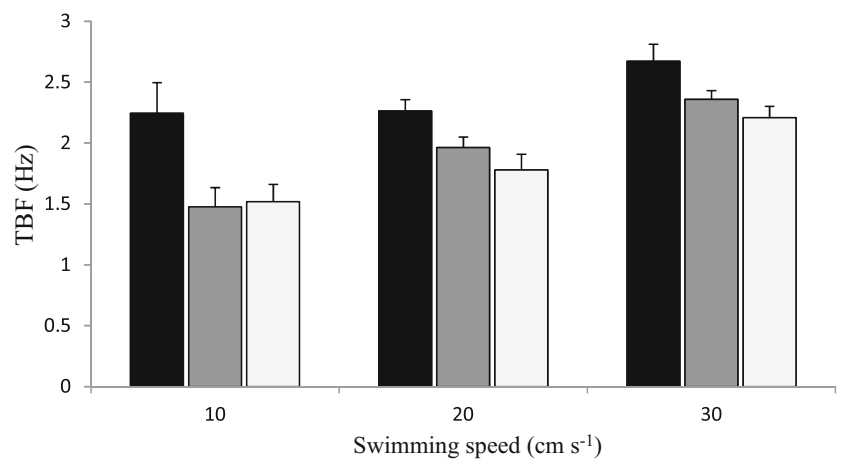

Fig. 3 Mean TBF (Hz) of the focal fish when swimming alone (black bars), in a school occupying the position rank \#1 (grey bars) and in a school occupying position rank \#2 to \#8 (pooled together), at three different swimming speeds. Values are mean \pm S.E.

of marginal means, $p=0.061$ ). Together, these results suggest that fish swimming at the front of the school gain an energetic advantage relative to swimming alone, but the effect of different ranks within the school is comparatively modest.

\section{Discussion}

Our study demonstrates that individuals in all of the positions tested relative to their nearest neighbour can gain an energetic advantage compared to when swimming alone: they do not need to be moving behind the nearest group-mate to save energy. The results clearly suggest that a reduction in costs of locomotion, potentially for all members, may be one of the primary drivers of schooling behaviours in fish.

The studies that have focussed on the energetic savings that trailing fish, swimming using axial locomotion, gain in a school have always assumed that leading fish show similar TBF to individuals swimming alone (Weihs 1973; Herskin and Steffensen 1998). Our values for energy saving, when comparing individuals swimming in anterior and posterior position relative to their closest neighbour in terms of oxygen consumption, are in the same range as previous estimates
(Herskin and Steffensen 1998). Our TBF analyses reveal, however, that energetic savings may be much more pervasive; even individuals swimming in the very front of the school are swimming at a lower cost than when they swim alone. Thus, the energetic advantages gained by individuals swimming within a school are more complex than previously envisioned. The theoretical mechanism originally proposed by Weihs (1973) was that fish trailing diagonally behind a leader could take advantage of reverse von Karman vortices (Liao et al. 2003a; Liao 2007) to reduce their cost of locomotion. Theoretical studies on virtual schools have since suggested that not only swimming side by side but also behind each other and in rectangular or diamond shapes could also provide energetic benefits compared to swimming in isolation (Hemelrijk et al. 2014). Furthermore, a swimming fish creates a zone of high pressure in front of them, similar to the "bowriding" process (Fish 2010) exploited by dolphins swimming in front of ships (Fish and Hui 1991) or pilot fish swimming in front of large sharks (Magnuson and Gooding 1971). Kinematic experiments have confirmed that fish can exploit high pressure generated on the upstream side of a cylinder (Liao et al. 2003b). Our results suggest that the fluid dynamics around the front of a fish swimming by axial locomotion can contribute to its neighbours swimming ahead; however, further studies, employing digital particle image velocimetry (DPIV), must be done to elucidate the physical dynamics that can allow anterior fish to save energy while swimming in front of their neighbours.

Our results also demonstrate that the position of an individual relative to its neighbour modulates the energy-saving benefits of group membership. These effects of spatial positioning on relative energetic expenditure may be particularly important in the face of environmental stressors, such as reduced oxygen availability or increased temperature (Killen et al. 2013). In these conditions, subtle differences in energy expenditure could become critical in determining the performance of individual group members. Hence, in the stressful situations described above, school dynamics may be affected, and diverge from optimal, with potential

Table 3 Summary of the linear mixed-effects model for the effects of swimming context and speed on tail beat frequency for juvenile mullet

\begin{tabular}{|c|c|c|c|c|c|c|c|c|c|c|}
\hline Term & Numerator df & Denominator df & $F$ & $p$ & Estimate & $\mathrm{t}$ & $p$ & S.E.M. & Lower $95 \% \mathrm{CI}$ & Upper $95 \%$ CI \\
\hline Intercept & 1 & 27.28 & 1371.59 & $<0.001$ & & & & & & \\
\hline Context & 2 & 31.59 & 29.66 & $<0.001$ & & & & & & \\
\hline Rank 1 & & & & & -0.546 & -6.04 & $<0.001$ & 0.09 & -0.728 & -0.364 \\
\hline Rank 2-8 & & & & & -0.638 & -7.47 & $<0.001$ & 0.09 & -0.811 & -0.466 \\
\hline Solitary & & & & & 0.000 & & & 0.00 & & \\
\hline Speed & 2 & 25.41 & 153.37 & $<0.001$ & & & & & & \\
\hline 10 & & & & & -0.671 & -17.01 & $<0.001$ & 0.04 & -0.751 & -0.592 \\
\hline 20 & & & & & -0.365 & -13.66 & $<0.001$ & 0.03 & -0.421 & -0.308 \\
\hline 30 & & & & & 0.000 & & & 0.00 & & \\
\hline
\end{tabular}


deleterious consequences for overall group performance and cohesion [e.g. increased shuffling rate among group members (Domenici et al. 2000, 2002)].

The finding that the energetic advantage gained by being in a school declines with increasing swimming speed may reflect an optimum benefit/speed relationship at lower speed and/or greater difficulty controlling position relative to neighbours at higher speeds. Increased inertia and consequently decreased manoeuvrability at high speeds may reduce the ability to exploit the flow of other school members (Hemelrijk and Hildenbrandt 2012). However, although the overall benefits of group membership decreased with speed, the effect on energy saving of position relative to neighbours was not modulated by speed, at least within the range of speeds examined in the current study.

There have been many studies of the relative cost and benefits of being in either the front or the back of animal groups (Krause and Ruxton 2002). These have demonstrated substantial trade-offs associated with foraging and predator avoidance, for example, individuals near the front of moving groups tend to obtain more food or higher quality food items but are more likely to be attacked by predators (Krause et al. 1998). Although all members of fish schools can gain an energetic benefit compared to swimming alone, trailing fish have a tendency (though not statistical significant) to save more energy than leading fish, and therefore, the position taken by an individual probably depends on an individual's need for energetic saving as well as on trade-offs related to foraging and predator avoidance. Moreover, individual fish with differing physiological (Marras et al. 2013) and personality traits (Stamps 2007) may preferentially select, over short temporal and spatial scales, specific positions relative to the neighbours (Killen et al. 2012). Future work should investigate how shuffling rates vary among individuals within schools and how positional shifts may influence energetic savings at the individual and the school levels. The current findings open up various novel avenues for studying interactions between the physiological and personality traits of individuals and their behaviour within a social context.

Our empirical demonstration that fish schooling can provide overall energetic advantages compared to swimming in isolation indicates that benefits of group living are more widespread among members than originally thought (Hemelrijk et al. 2014). The shared adaptive value of schooling may therefore be strongly related to these energetic benefits.

Acknowledgments We thank C.K. Hemelrijk for the useful comments on an early draft of the manuscript. SSK was supported by NERC Advanced Fellowship NE/J019100/1.

Ethical standards The fish were held, and the non-lethal experiments were conducted, in strict accordance with the laws governing animal experimentation in France. The experiments were performed by the holder of an animal experimentation licence issued by the University of Montpellier (DJM, Formation Experimentation Animale niveau 1, numéro d'agrément de la formation I-UnivMontp-F1-06). The S.M.E.L. facility, where the fish were held and the experiments performed, is recognised by the University of Montpellier as a certified facility for fish rearing and ecophysiological experimentation.

Conflict of interest The authors declare that they have no conflict of interest.

\section{References}

Bates D, Maechler M, Bolker B (2011) lme4: Linear mixedeffects models using S4 classes. 0.999375-3, R package version, http://cran.r-project.org/package=lme4

Belyayev N, Zuyev GV (1969) Hydrodynamics hypothesis of schooling in fishes. J Ichthyol 9:578-584

Bumann D, Krause J, Rubenstein D (1997) Mortality risk of spatial positions in animal groups: the danger of being in the front. Behaviour 134:1063-1076

Cutts C, Speakman J (1994) Energy savings in formation flight of pinkfooted geese. J Exp Biol 189:251-261

Domenici P, Ferrari RS, Steffensen JF, Batty RS (2002) The effect of progressive hypoxia on school structure and dynamics in Atlantic herring Clupea harengus. Proc R Soc Lond B 269:2103-2111

Domenici P, Steffensen JF, Batty RS (2000) The effect of progressive hypoxia on swimming activity and schooling in Atlantic herring. $\mathrm{J}$ Fish Biol 57:1526-1538

Dominy RG (1992) Aerodynamics of grand prix cars. J Autom Eng 206: 267-274

Fish FE (1999) Energetics of swimming and flying in formation. Comments Theor Biol 5:283-304

Fish FE (2010) Swimming strategies for energy economy. In: Domenici P, Kapoor BG (eds) Fish locomotion: an eco-ethological perspective. Science Publisher, Enfield, pp 90-122

Fish FE, Fegely JF, Xanthopoulos CJ (1991) Burst-and-coast swimming in schooling fish (Notemigonus crysoleucas) with implications for energy economy. Comp Biochem Physiol 100A:633-637

Fish FE, Hui CA (1991) Dolphin swimming — a review. Mammal Rev 21:181-195

Godin J-GJ (1997) Evading predators. In: Godin J-GJ (ed) Behavioural ecology of teleost fishes. Oxford University Press, Oxford, pp 191-236

Hemelrijk CK, Hildenbrandt H (2012) Schools of fish and flocks of birds: their shape and internal structure by self-organization. Interface Focus 2:726-737

Hemelrijk CK, Reid DAP, Hildenbrandt H, Padding JT (2014) The increased efficiency of fish swimming in a school. Fish Fish. doi:10.1111/faf.12072

Herskin J, Steffensen JF (1998) Energy savings in sea bass swimming in a school: measurements of tail beat frequency and oxygen consumption at different swimming speeds. J Fish Biol 53:366-376

Johansen JL, Vaknin R, Steffensen JF, Domenici P (2010) Kinematics and energetic benefits of schooling in the labriform fish, striped surfperch Embiotoca lateralis. Mar Ecol Prog Ser 420:221-229

Killen SS, Marras S, Metcalfe NB, McKenzie DJ, Domenici P (2013) Environmental stressors alter relationships between physiology and behaviour. Trends Ecol Evol 28:651-658

Killen SS, Marras S, Steffensen JF, McKenzie DJ (2012) Aerobic capacity influences the spatial position of individuals within fish schools. Proc R Soc Biol Sci Ser B 279:357-364

Krause J, Bumann D, Todt D (1992) Relationship between the position preference and nutritional state of individuals in schools of juvenile roach (Rutilus rutilus). Behav Ecol Sociobiol 30:177-180 
Krause J, Godin JGJ (1995) Predator preference for attacking particular group sizes: consequences for predator hunting success and prey predation risk. Anim Behav 50:465-473

Krause J, Ruxton GD (2002) Living in groups. Oxford University Press, Oxford

Krause J, Ruxton GD, Rubenstein DI (1998) Is there an influence of group size on predator hunting success? J Fish Biol 52: 494-501

Liao JC (2007) A review of fish swimming mechanics and behaviour in altered flows. Philos Trans R Soc B 362:1973-1993

Liao JC, Beal DN, Lauder GV, Triantafyllou MS (2003a) Fish exploiting vortices decrease muscle activity. Science 302:1566-1569

Liao JC, Beal DN, Lauder GV, Triantafyllou MS (2003b) The Karman gait: novel body kinematics of rainbow trout swimming in a vortex street. J Exp Biol 206:1059-1073

Magnuson JJ, Gooding RM (1971) Color pattern of pilotfish (Naucrates ductor) and their possible significance. Copeia 1971:314-316

Marras S, Batty RS, Domenici P (2012) Information transfer and antipredator maneuvers in schooling herring. Adapt Behav 20:44-56

Marras S, Domenici P (2013) Schooling fish under attack are not all equal: some lead, others follow. PLoS ONE 8:e65784

Marras S, Killen SS, Domenici P, Claireaux G, McKenzie DJ (2013) Relationships among traits of aerobic and anaerobic swimming performance in individual European sea bass, Dicentrarchus labrax. PLoS ONE 8:e72815

Marras S, Porfiri M (2012) Fish and robots swimming together: attraction towards the robot demands biomimetic locomotion. J R Soc Interface 9:1856-1868

McCole SD, Claney K, Conte JC, Anderson R, Hagberg JM (1990) Energy expenditure during bicycling. J Appl Physiol 68:748-753
Nakagawa S, Schielzeth H (2013) A general and simple method for obtaining $\mathrm{R}^{2}$ from generalized linear mixed-effects models. Methods Ecol Evol 4:133-142

Pitcher TJ, Parrish JK (1993) Function of shoaling behaviour in teleosts. In: Pitcher TJ (ed) Behaviour of teleost fishes. Chapman \& Hall, London, pp 363-439

Portugal SJ, Hubel TY, Fritz J, Heese S, Trobe D, Voelkl B, Hailes S, Wilson AM, Usherwood JR (2014) Upwash exploitation and downwash avoidance by flap phasing in ibis formation flight. Nature 505 : 399-404

Poulin R (1999) Parasitism and shoal size in juvenile sticklebacks: conflicting selection pressures from different ectoparasites. Ethology 105:959-968

Stamps JA (2007) Growth-mortality tradeoffs and 'personality traits' in animals. Ecol Lett 10:355-363

Svendsen JC, Skov J, Bildsoe M, Steffensen JF (2003) Intra-school positional preference and reduced tail beat frequency in trailing positions in schooling roach under experimental conditions. J Fish Biol 62:834-846

Usherwood JR, Stavrou M, Lowe JC, Roskilly K, Wilson AM (2011) Flying in a flock comes at a cost in pigeons. Nature 474:494-497

Videler JJ (1993) Fish swimming. Chapman \& Hall, London

Webb PW (1993) The effect of solid and porous channel walls on steady swimming of steelhead trout Oncorhynchus mykiss. J Exp Biol 178: 97-108

Weihs D (1973) Hydromechanics of fish schooling. Nature 241:290-291

Weimerskirch H, Martin J, Clerquin Y, Alexandre P, Jiraskova S (2001) Energy saving in flight formation. Nature 413:697-698

Zuur AF, Ieno EN, Meesters EHWG (2009) A beginner's guide to R. Springer, New York 